\title{
Criminologie
}

\section{Document : De divers modes de financement de la construction des prisons}

Volume 18, numéro 1, 1985

L'histoire du contrôle social

URI : https://id.erudit.org/iderudit/017206ar

DOI : https://doi.org/10.7202/017206ar

Aller au sommaire du numéro

Éditeur(s)

Les Presses de l'Université de Montréal

ISSN

0316-0041 (imprimé)

1492-1367 (numérique)

Découvrir la revue

Citer ce document

(1985). Document : De divers modes de financement de la construction des prisons. Criminologie, 18(1), 40-42. https://doi.org/10.7202/017206ar d'utilisation que vous pouvez consulter en ligne.

https://apropos.erudit.org/fr/usagers/politique-dutilisation/ 


\section{DE DIVERS MODES DE FINANCEMENT DE LA CONSTRUCTION DES PRISONS}

Les administrations gouvernementales contemporaines se préoccupent de la croissance des coûts. Cela vaut pour la construction des prisons comme pour le reste. Y a-t-il lieu de s'inspirer des méthodes de nos proches ancêtres? En voici deux, à titre d'exemples.

La première qui est rapportée plus bas visa à financer la construction de la seconde prison de Montréal, en 1793, dans le Vieux Montréal. Elle est notamment expliquée par une lettre du gouverneur Haldimand à Lord North. Incendiée en 1803, la prison fut remplacée par une nouvelle en 1806 . C'est pour assumer les coûts du nouvel édifice ainsi que ceux de la prison de Québec qu'on eut recours à une autre méthode de financement.

Le premier document est tiré de Borthwick, J.D. (1907), History of the Montreal Prisons, Montréal, The Gazette Printing Co. Ltd.

Le second est tiré des Statuts provinciaux du Bas-Canada, 1805 , c. 13 , a. 6 . 
QUEBEC, 31at July, 1783.

My Lord,-I have the honor to transmit a copy of the proceedings of the Legislative Council during the last session and the ordinances which bave been passed in it, and to which my assent has been given.

I had some reluctance to give my assent to the Ordinance for raising by lottery a sum of money for the purpose of building a prison at Montreal, but as a prison was necessary and is I think it very unjust that the money of the British nation should be employed in providing local conveniences for the inhabitants of this province, I gave my assent to it.

My Lord,-

Your Lordship's most obedient and most humble servant, FRED. HALDIMAND.

Right Honorable Lord North.

Endorsed, Quebec, 31st July, 1783.

GOV. HALDIMAND.

\section{No. 890 . District de Montreal.}

LE PORTEUR de ce BILLET, en consequence d'une ORDONNANCE du Gouverneur \& Conseil Législatif de cette Province, passée dans la VINGT TROISIEME Année du Regne de SA MAJESTE, recevra pour BENEFICE, le Prix qui appartiendrs audit Billet de ladite LOTTERIE, qui se tirera conformément à ladite ORDONNANCE; pour-vu que le TIRAGE soit fait le ou avant le troisieme jour de Février 1784, ou l'argent sera remboursé en rendant le Billet, sans déduction. 
VI. Et afin de défrayer les dépenfes qui feront encoutrues pour eriger les dites Prifons Communes: Qu'il foit done de plus ftatué par l'autorité fuldite, que depuis es après la paftatıon de cet AEte, itl fera levé, perçu, recueilli et payé, pour at fur les Marchandifes et Effets refpectifo ci-après mentionnés, qui feroot importés ou apportés dans aucune partic de cette Province, d'aucune place ou places d'où iceux peuvent âtre léga:ement importes, en lus et pardeffus tous autres Droits maintenant inpolés et payables fur jceux dans cette Province, en vestu, d'aucun Acte ou ACles du Parlement de la Grande Bretagne, ou du Parlement Provincial. de cette Province, les différens taux es droits fujvans, c'eft-à-dire: Premièrement, pour chaque livre, (dite avoirdupoids) de Thé bou, deux deniers. Secondemezt, pour chaque livre (même poids) de The fouchong ou autres Thés noirs, quatro deniers. Troifìmement, pour chaque livre (méme poids) de ThéHylfon, fix deniers. Quatrièmement, pour chaque livre (méme poids) de tous autres Thés verts, quatre deniers. Cinquic̀mement, pour chaque Galion (nefure Angloife) de tous Ejprits ou autres Liqueurs fortes, trois deniers. Sixièmement, pour chaque Gallon (même mefure) de toute efpèce de $V t n$, tzois densers. -Septièmement, pour shaque Gallon (même mefure) de Melaffe et Sirop, deux deniers, Et fujvant ces rax pour aucune quantité plus ou moins grande de teis atricles refpetivement. 